\section{PRAIRIE POINTSMANSHIP: HERE'S HOW}

Fritz J. Logan, The University of Alberta, Edmonton

Herein I briefly describe my writing course, explain how it works, and argue its general applicability: since there is always a point to make, and since the act of articulating and making that point always helps to bring under control the smaller elements-words, sentences, paragraphs--of prose composition, the point is central and crucial. In AgFor 204 and in this consideration of it the point is the point.

This subject of pointsmanship is crucial because the ability to make one's point is arguably the most important skill that the University person takes along into his or her career; whatever other tools the successful professional may use, printed and spoken words--clear, strong, precise--quickly become the primary tools. Unfortunately, it is beyond argument that most young professionals lack this persuasive skill. Why? Because of a subtle and subconscious missed opportunity on the part of those whose job it is to teach this skill of mirroring in words one's perceptions of truth. That is, the priorities for all serious writing are and must be: first, quality of thought; two, quality of expression; three, quality of presentation. But post-secondary writing courses-"technical," "creative," "advanced," "remedial," "practical"-tend unfortunately to stress two and three at the expense of one. This we all know. What we do not think much about are the consequences: that if most of North America's writing courses stress the expression and embellishment of a nonexistent or factitious idea, then the resulting misdirected effort is enormous. This misdirected effort is as regrettable as it is needless, and its avoidance by millions of young people over billions of career days and writing tasks is obviously important. Thus this subject is justified as being worth our attention, and, as orwell put it, "Is not frivolous and is not the exclusive concern of professional writers."

Let's define a few terms and then take a look at the course itself. First, let's make a clear distinction between "training" and "eduaction": training is the inculcation of a skill; education is, to paraphrase St. Thomas, the process by which we strengthen the mind that it might better apprehend truth. The two functions are overlapping but distinct. In my course we are concerned primarily with education and only secondarily with training. Second, let's note the equally clear and crucial distinction between "central" and "peripheral": central for our purposes means pertinent to the point; peripheral means pertinent merely to the topic. Third, let's blur the distinction commonly made between "technical" writing and other kinds: we are all technical writers, except those of us who are artists, and even our artist friends spend most of their museless time as artisans, technicians. Like Richard Hof staedter's intellectual, we are all much more concerned with applying rules and reason than with o'erleaping them on the viewless wings of inspiration. So let's talk about simply "writing" and not worry too much about what kind. Not yet. Finally, by "professional" I mean persons whose chlef stock-1n-trade is the application and communication of thought. 
What, then, is there to say about the writing course in question? Where did it come from and where is it going?

This course, AgFor ("Agriculture/Forestry") 204, is offered in the spring and fall by The University of Alberta's Faculty of Agriculture and Forestry, and has been offered since 1929. Although the course has changed in its accidentals during this time, it has kept as its essential purpose the increased effectiveness of young professionals' use of written and spoken English. I inherited the course from C. F. Bentley, the eminent Soll Scientist and distinguished former Dean of our Faculty who taught the course for thirty years, having inherited it from his predecessor, and so forth. In the past $f$ ive years the course has become perfused increasingly with the affable and excellent spirit of my own peerless teacher, M. L. Ross, Professor, Department of English, The University of Alberta.

So, many of us have taught the course (a11, I believe, with the same basic objectives in mind) and anyone could teach it--anyone, that is, with three qualifications: the ability to write English, the ability to communicate this skill, and a grasp of the disciplines on which his or her students will likely be writing. (By "grasp" here I mean an understanding of the key terms and concepts of these disciplines, plus a feel for the state of the art, for the current authentic issues.) And who takes the course? Seventyfive per cent are Aggies, for most of whom it is mandatory, and the rest are from the other faculties: Engineering, Arts, Science, Business Administration, Education, and Physical Education. In all its long history the course has neither had nor seemed to require a motto, yet if we suddenly felt the need for one, I believe, and feel my predecessors would agree, that we could do worse than Quintilian's remark about writing "not that we may be understood, but that we may not be misunderstood." of what, then does the course consist? Below is Figure One, last term's schedule. There are, after the class meeting dates on the left, three main columns: "Reading," "Speaking," "Writing."

The "Reading" column is a breakdown of the pages to be read from the text, Words, Sentences, Paragraphs, Essays (Holt, Rinehart and Winston of Canada, 1982) by Professor C. Gordon Moyles and myself. This text, the title of which is also its table of contents, is the brainchild of Joe McKeon, then Holt's Acquisitions Editor and now a senfor editor with William C. Brown. Mr. McKeon wanted a different sort of composition book, one which would be in effect a tool for the writing of essays in English; which would also cover words, sentences, and paragraphs; which would also stand a good chance, through whatever presentational skills Dr. Moyles and I might possess, of actually being read. To that end we packed this streamlined little volume with fllustrative quotes, parodies, and snippets of verse. Without pandering, or sacrificing the matter to the manner in any way, we tried to make the book as funny and readable as we possibly could. And we have been gratifled at the numerous adoptions of Words in the few months since its publication.

So much for "Reading"; under "Speaking" are five speeches given by all AgFor 204 people. First, they introduce themselves, then they evaluate a book of their cholce which bears on their proposed essay topic, then they evaluate an article of their choice which also bears on their proposed topic, then they briefly defend their proposed title and outline, and finally they give their major 
AG FOR 204 SCHEDULE - FALL' '82

\begin{tabular}{|c|c|c|c|c|c|c|c|c|c|c|}
\hline \multicolumn{3}{|c|}{ READING } & \multicolumn{2}{|l|}{ SPEAKING } & \multicolumn{2}{|l|}{\begin{tabular}{|l} 
WR I TING \\
IN-CLASS \\
\end{tabular}} & \multicolumn{2}{|l|}{$\begin{array}{l}\text { Short } \\
\text { Term }\end{array}$} & \multirow[t]{2}{*}{$\begin{array}{l}\text { Long } \\
\text { Term }\end{array}$} & \multirow[b]{2}{*}{ Due } \\
\hline Sept. 13 & $M \& L$ & bue & & Due & & Due & & Oue & & \\
\hline $15 \begin{array}{l}14 \\
16 \\
\end{array}$ & $\begin{array}{rr}\text { P.P } & 1-3 \\
& 4-6 \\
\end{array}$ & & $\begin{array}{l}\text { Self - } \\
\text { Introduction }\end{array}$ & $15 / 16$ & $\begin{array}{l}\text { Edi torial } \\
\text { Quizzes }\end{array}$ & $13 / 14$ & & & & \\
\hline $\begin{array}{r}17 \\
20 \\
\end{array}$ & $\begin{array}{c}7-9 \\
10-12 \\
\end{array}$ & & & & & & & & Topic & $14 / 15$ \\
\hline $\begin{array}{r}22 \\
22 \\
23\end{array}$ & $\begin{array}{l}13-15 \\
16-18 \\
\end{array}$ & & & & & & Letter $\$ 1$ & $23 / 24$ & & \\
\hline $\begin{array}{ll}24 & \\
27 & 28 \\
\end{array}$ & $\begin{array}{r}19-21 \\
22-26 \\
\end{array}$ & $28 / 29$ & & & & & & & $\begin{array}{l}\text { Revised } \\
\text { Topic }\end{array}$ & $21 / 22$ \\
\hline 2930 & $32-34$ & & & & & & $\mid \begin{array}{c}\text { Exercises } \\
0.1\end{array}$ & $30 \%$ & & \\
\hline \begin{tabular}{lll|} 
oct. & 1 & \\
& 4 & 5 \\
\end{tabular} & $\begin{array}{l}35-37 \\
38-40 \\
\end{array}$ & & Book & $4 / 5$ & & & & & Arcument & $28 / 29$ \\
\hline $\begin{array}{ll}6 & 7 \\
8 & 7 \\
\end{array}$ & $\begin{array}{l}41-43 \\
44-46 \\
\end{array}$ & & Evaluation & & & & Resume & $7 / 8$ & & \\
\hline 12 & $\begin{array}{l}47-49 \\
50-52\end{array}$ & & & & & & & & Research & $12 / 13$ \\
\hline \begin{tabular}{ll|}
13 & 14 \\
15 & \\
\end{tabular} & $\begin{array}{l}53-55 \\
56-58\end{array}$ & & & & & & Letter $\$ 2$ & $14 / 15$ & & \\
\hline $\begin{array}{rr}18 & 19 \\
20 & 19 \\
\end{array}$ & $\begin{array}{l}59-61 \\
62-64 \\
\end{array}$ & & |Paper & $18 / 19$ & & & & & \begin{tabular}{|l|} 
Revised \\
Argument \\
\end{tabular} & $19 / 20$ \\
\hline $22^{21}$ & $65-68$ & $20 / 21$ & Evaluation & & & & \begin{tabular}{|l|} 
Book \\
Evaluation
\end{tabular} & $21 / 22$ & & \\
\hline $\begin{array}{l}2626 \\
2726 \\
\end{array}$ & $\begin{array}{l}72-74 \\
75-77 \\
\end{array}$ & & & & & & & & Title & $26 / 27$ \\
\hline Nov. $\quad 1^{28}$ & $\begin{array}{r}78-80 \\
81-83 \\
\end{array}$ & & Outline & $1 / 2$ & & & $\begin{array}{l}\text { Exerclses } \\
\text { Eh. } 2\end{array}$ & $28 / 29$ & & \\
\hline $\begin{array}{|ll|}3 & 2 \\
& 4 \\
\end{array}$ & $84-86$ & & $\begin{array}{l}\text { T1tle } \\
\text { Defense }\end{array}$ & & & & & & outline & $2 / 3$ \\
\hline $\begin{array}{ll}5 & \\
8 & 9\end{array}$ & $\begin{array}{l}87-89 \\
90-92\end{array}$ & $9 / 10$ & & & & & $\mid$\begin{tabular}{|l|} 
Paper \\
Evaluation
\end{tabular} & $4 / 5$ & & \\
\hline $\begin{array}{l}10 \\
12 \\
\end{array}$ & $98-100$ & & & & & & & & $\begin{array}{l}\text { Revised } \\
\text { Outline }\end{array}$ & $9 / 10$ \\
\hline $\begin{array}{ll}15 & 16 \\
17 & \\
\end{array}$ & $\begin{array}{l}101-103 \\
104-106 \\
\end{array}$ & & $\|$ Major & $15 / 16$ & Logle & & $\begin{array}{c}\text { Exercises } \\
0.3\end{array}$ & $9 / 10$ & & \\
\hline $19^{18}$ & $\begin{array}{l}107-109 \\
110-112 \\
\end{array}$ & & Presentation & & Quiz & & & & \begin{tabular}{|l} 
Rough \\
Draft \\
\end{tabular} & $16 / 17$ \\
\hline 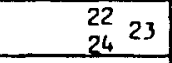 & $\begin{array}{l}113-115 \\
116-118 \\
\end{array}$ & & & & & & & & & \\
\hline $26^{25}$ & $\begin{array}{l}119-121 \\
122-124 \\
\end{array}$ & & & & & & & & $\begin{array}{l}\text { First } \\
\text { Draft }\end{array}$ & $23 / 24$ \\
\hline 2930 & $\begin{array}{l}125-127 \\
129-131 \\
\end{array}$ & & & & & & & & & \\
\hline $\begin{array}{lll}\text { Dec. } & 1 & 2 \\
\end{array}$ & $\begin{array}{l}132-133 \\
134-136 \\
\end{array}$ & & & & & & & & Edit & $30 / 1$ \\
\hline $\begin{array}{ll}6 & 7 \\
8 & \\
\end{array}$ & $\begin{array}{l}137-139 \\
140-141 \\
\end{array}$ & $8 / 9$ & & & Dfinal (?) & $19 / 10$ & & & & \\
\hline $10^{9}$ & & & & & $\begin{array}{l}\text { Agfor } 204 \\
\text { Evaluation }\end{array}$ & $9 / 10$ & & & $\begin{array}{l}\text { Second } \\
\text { Draft }\end{array}$ & $7 / 8$ \\
\hline
\end{tabular}

presentation, that is, they deliver their essay ("Writing, LongTerm"), with modifications, orally. These speeches are all composed following specific guidelines and evaluated against specific criteria. The middle speech, the critique of the technical paper, we videotape in order that my people can see themselves in action. We have found that, when thus used, a videotape is worth a million words of criticism, however insightful and kindly meant. Because I do not here wish to digress and list the ways in which the spoken and written assignments complement each other, I will simply note that class time spent on speeches is very well spent indeed.

That brings us to "Writing"; this column is subdivided into three. The first sub-column under "Writing," "In-Class," takes in all the tests, the bulk of which are what I call "editorial quizzes" (see Figure Two). These comprise ten more or less bizarre sentences lif ted from their predecessors' assignments over the years and represented to the current group in quiz form. The assumption here is that few of my people can read critically and aggressively, but that they should be able to, all of them, if their professional opinions are ever likely to be worth much. Put another way, the ability to avoid mistakes in composition presupposes the ability to spot them as mistakes. Therefore quizzes, till week ten, every class day.

Besides these editorial quizzes there is a quiz on basic $\log 1 c$, a short final, and, an the last day, an "AgFor 204 Evaluation" (see Figure Three). 


\section{FORTY.SIX}

1. As shown by the attached graph, as class size increases, attitudes, instruction, and achievement decreases (10). Pupils develop better attitudes toward their work; they become more interested in the material and are less disruptive (9).

2. Men and women over 65 have low incomes and are frequentlywidowed persons.

3. It has been shown to increase the efficiency of nitrogen utilization by Armstrong ( 9 ).

4. It has been shown in experiments that products such as cough suppressants and lozenges and also some 1 ip creams, such as "B11stex" contain up to 5,000,000 p.p.m. of phenol and they are all ingested directly.

5. However, after the pups reach sexual maturity, they enjoy a mortality rate of only 20 per cent (5).

6. Over half the formerly married.. . mothers of pre-schoolers

- are employed, only a third of married preschool-mothers (Bureau of Labor Statistics, $1975 /$ a 7 ).

7. Effectiveness and easy handling of phenol enables the beekeeper to cut down labor costs by up to 500 per cent, which directly results in lower overhead, therefore, a less costly product.

8. A hitching ratl is just north of the corrals strung up between two trees.

9. Most of their minds were to distorted to walk, some of them got dragged into a red station wagon.

10. Though extremely wrinkled, her eyes sparkle as she gazes into the past to recall unforgettable incidents.

FIGURE 2

\section{AG FOR 204 EVALUATION}

Logan

1. What course aspect(s), if any, did you particularly dislike?

2. What course aspect(s), if any, did you particularly like?

3. What would you cut, or de-emphasize?

4. What would you expand, or emphasize?

5. What would you add?

6. Do you think AgFor 204 should be a full-year course?

7. AgFor 204 is supposed to improve, significantly, the communicative skills (reading, writing, speaking) and confidence of Agriculture/Forestry professionals; do you think it does this?

8. Other comments.

FIGURE 3

This last is excellent feedback--student criticisms and suggestions-and has helped me greatly in tinkering with the course over the years and modifying it to its present form. The "Evaluation" done, so is all their in-class writing.

"Short-term" writing subsumes a number of little odd-jobs: they write a letter of application for employment, they do as many of the exercises (in Chapters 1-3 of the text) as they feel are necessary, they compose a resume, they write for information to some 
appropriate agency, and they write up the book and paper evaluat lons, delivered earlier orally. These little writing assignments are worth doing and knowing how to do, and they keep the typewriter keys in motion, but they are not the term's main event. The term's main event is the last culumn on the right, "long term." This is their major paper, all six pages of it, broken down into twelve component assignments. (This last column also mirrors the organization of Chapter Four, "Essays," which provides step-by-step instructions in minute detail.) First, my people come up with a topic which interests them, about which they have some first-hand knowledge, and to which their chosen field of study is somehow related. These three stipulations bear heavy emphasis because here is where their originality, perhaps long dormant, is lurking. This is where their point will be, and it is crucial to pin it down and take a good look at it now, at the outset. Why? Because no point, no originality, no paper. And no reason to assume that they will spontaneously become original later on. Not to educe and articulate the point is the missed opportunity referred to earlier.

After revising their topic a few $t$ imes they will arrive at their point (thesis, argument), and after a bit of research they will revise this point, of ten several times and of ten as late as the first draft stage. Soon they arrive at an interim title and out11ne, both of which they will put on the screen and defend, then move to a rough draft and finally a first draft, typed.
At this point the composition process takes an interesting turn:

my people edit each other's papers, according to guidelines set in Chapter Four, before I see these papers. This exercise demonstrates that editing is work and that the resultant informed opinion about a given piece of writing is worth listening to but, because this opinion is also the product of a human $m$ ind, is not to be taken as gospel. The writer tries to come at the truth of some phenomenon or other; the editor tries to come at the truth of the paper; but the truth is always seen through a glass darkly, so there must be some writer/editor give and take at this point. Finally, the writer must decide, on the basis of my comments and his or her editor's, whether to leave the paper as it 1s, do a second draft, refute the criticisms, or arrive at some compromise between these options.

And that's it, minus a few library tours, VTR viewings, and slide presentations. At the end of the term my people each get back a file folder containing all their assignments, my notes to their speeches, and their final grade. The end. Exit smiling.

"Really?" The question seems almost to ask itself at this functure. "Do they all exit smiling?" (Well, no.) "More to the point: do they all exit 1iterate?" Obviously I am an AgFor 204 partisan; it might be wise to consider a few objections which might be raised against the AgFor method by one less commltted, one more disinterested, though not uninterested.

For example, a veteran comp. teacher might well object to this absolute insistence on an arguable point. Such insistence 1s, he 
or she might say, unrealistic; many students can't or won't come up with anything even remotely original, and the strain this requirement puts on student and teacher is simply unreasonable.

Thus some might say that, however laudably high-minded the approach might seem, the reality will prove too difficult. What can I say to that? Simply that I have not found it so. The approach is difficult, yes, but not excessively, and it gets easier once the initial hurdles of topic and argument have been ileared. Furthermore, the approach gets easier term by term as incoming students hear via the grapevine what is expected of them; if they expect to work hard, to articulate and make a valid point, then they will.

Also and fina1ly, difficulty is relative; other approaches, though less demanding intellectually, make heavy demands on everyone's patfence. That is, I well recall the bad old days when neither nor my students would have recognized a valid point if we sat on one. We were thus obliged to concentrate our energies on the expression and embellishment of factitious, poorly articulated, and nonexistent thoughts. I did precisely what I said, in my introductory remarks to this paper, that we should not do. And my people and I thus found ourselves engaged in a bitterly dismal charade of manner over matter, a meaningless, endless, comnaflddling chore. Anything is easier than that.

One might grant that the AgFor approach is possible, however, and perhaps even desirable, but object that it is one-sided; there are, after all, other essay forms besides the persuasion. Granted, there are other forms, but a good persuasion requires quite a bit of describing, narrating, and explaining, in the introductory pages especially, before the essay gets off the ground. Furthermore, I would state it as a matter of informed opinion that persuasion is the most interesting, challenging, and enjoyable of the four forms. Also, many seemingly straightforward expository essays are actually disguised persuasions; a bias is, after all, only a thesis in ambush. Fourth, details considered for inclusion in the other three forms are selected or rejected on the basis of some organizing principle--you can't include everything about anything after all-and this organizing principle is a thesis in embryo. Finally, the salient point about professionals is that they profess. Their colleagues and the general public want to know what they think, and it's helpful if the professionals themselves know. Therefore, and other things being equal, careers tend to advance with increasing skill at adopting, articulating, and carrying one's point--clearly, fairly, strongly, and persuasively.

One might, however, concede the possibility and primacy of a valid argument, but for our intellectual elite only: not everyone who takes technical writing courses is, after all, a "professional," even in the broadest possible sense of the word; some tech. writers are such ultra-technical technictans that, it might be argued, no one will ask them for their opinions about anything, ever. What about these people? The course is thus seen to be elftist. This objection, the weakest so far, would have more force if it were less absurd: an idea is an idea, whether or not it has the power to whisk its conceiver eventually to Stockholm. To advocate the preclusion of certain people from the realm of opinton, and relegate them perpetually to the below-stairs realm of raw data, is to advocate decapitation of foot soldiers because they will never be strategists. This is elitism with a vengeance. 
Finally, one might ask, by way of objection, what else is new?

That is, most writing teachers agree with these principles in principle. There yawns, however, a huge gulf between intellectual assent and knowledge, another between knowing and knowing how, and another between knowing how and doing. From most students' papers one might infer only with great difficulty their teacher's familiarity with the Poetics.

Having considered the four points of tenest raised against the AgFor method, let us now consider a few points which support my original contention, that the method is generally applicable.

There are, for example, training benefits associated with educing, early on and at whatever cost in effort, an arguable point, and then painstakingly working through the twelve or so steps in the composition of a proper essay. The chief benefit is the ease with which the elements of prose fall into 1 ine. Suddenly it makes sense that an essay should have a beginning, middle, and end; that these should all have, if not subheadings, at least subdivisions; that these various subdivisions comprise paragraphs of varying lengths with functional openers, clinchers, and transitions; that these paragraphs be composed of sentences bearing maximum meaning per word; and that these words--"the right ones in the right order"--be grammatical, properly spelled, helpfully adorned and cordoned off by punctuation. To repeat our general guiding principle: pertinence, not merely to the subject but to the point; once this is seen to make basic sense, then the specific niceties of expression and presentation, and the need for them, are also seen to make sense. We are trained to train others in these niceties, and whatever eases the labor on both sides of the podium is all to the good.

Besides training benefits, there are the much more important educational ones. That 15 , the student has gained the satisfaction of having been somewhat "led out," of having had a glimpse of truth by the light reflected between the language and his intellect, of having finally got it right. And the teacher? He or she has helped make the most of a human mind. I believe that to give such help is the best thing one person can do for another, and the teacher has the satisfaction of having done just that. So the educational benefits, unquantifiable and intangible, are nonetheless real, lasting, and great.

The final point that I raise in support of the AgFor method's general applicability is that it has been and is being generally applied. Thus we have moved from "should" (points one and two) to "is." Where, how, and on whom? On, first of all, undergrads in eastern and western Canada--artsmen, aggies, education and physical education majors, foresters, pre-vets, food science people, engineers, commerce majors, chemists, social science people, physicists, and so forth. Their work, the evaluations done on the last class day, and follow-up quest fonnaires done after an interval of five years--all these indicate that a real and signif icant benefit, perceived as such, has been conferred. Furthermore, through the U. of A's Faculty of Extension, I have used the method, modified, on a wide range of mature students: doctors, lawyers, housewives, fullbacks, and ballerinas. Finally, I have kept the method intact though modified, while drastically telescoping the course, and offering this as a one day communications seminar to people in business and government. 
To sum up: I have here described AgFor 204 and the AgFor 204 method, defining terms as necessary while stressing the importance of the topic, going briefly into the history of the course, touching on ideals and principles, then considering in some detail the course schedule. Having thus provided a little background, I noted some points that are and have been raised against the AgFor method--obviousness, difficulty, one-sidedness, elitism-and, being unable to concede much to any of these points, I concluded by noting a few points--perceived benefits, long and varied use--in its favor. Throughout I have argued the wide applicability of this method, old with Socrates, by which we grub around and grunt and sweat to discover what we want to write before we write it, by which the tough and cruclal work of essay writing is done long before the dust cover comes off the typewriter, by which we may hope to catch and convey a glimpse of truth.

Let's leave the last word to St. Paul, who seldom failed to make his point, and in so doing incidentally gave my university its motto--Quaecumquae Vera: "Whatsoever things are true, whatsoever things are honest, whatsoever things are just, whatsoever things are pure, whatsoever things are lovely, whatsoever things are of good report if there by any virtue, and if there by any praise, think on these things."

$$
\text { ................... }
$$

Dr. Logan is a Professor in the Faculty of Agriculture at the University of Alberta, Edmonton. 